\title{
Report
}

\section{Community-based diabetes programme: the micro-clinic project} D.E. Zoughbie ${ }^{1}$

$$
\text { برانيالز زغبي السكري المجتمعي المرتكز: مشروع العيادة المكروية }
$$

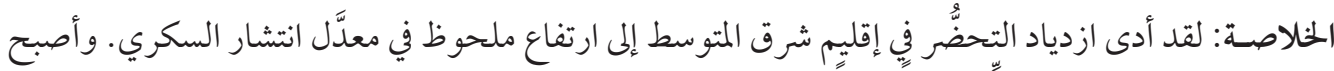

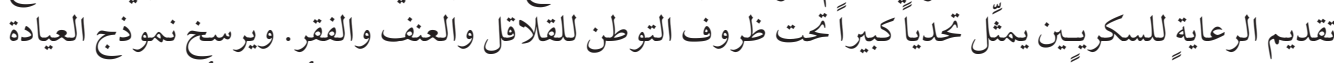

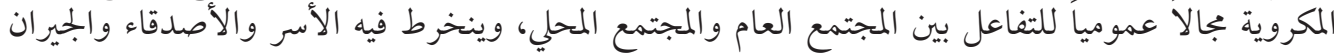

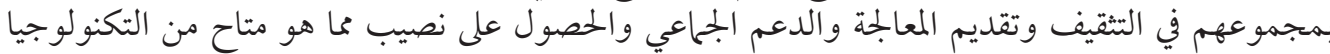

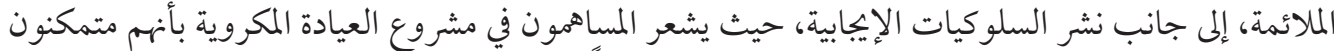

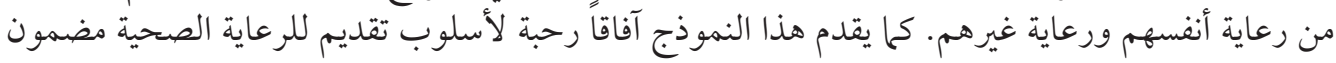

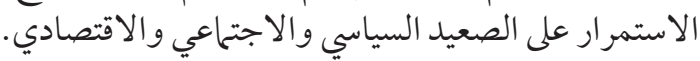

ABSTRACT Increased urbanization in the Eastern Mediterranean Region has led to a significant rise in the prevalence of diabetes. Caring for diabetes under conditions of endemic uncertainty, violence and poverty is a great challenge. The micro-clinic model establishes a public domain of social and community interaction whereby friends, families and neighbours can collectively engage in education, treatment and group support, obtain shared access to appropriate technology and spread positive behaviours. Participants who are active in micro-clinics feel empowered to care for themselves and others. The micro-clinic model offers the prospect of an economically, socially and politically sustainable approach to health care.

\section{Programme de lutte contre le diabète à l'échelon local : le projet de microclinique}

RÉSUMÉ L'urbanisation croissante dans la Région de la Méditerranée orientale a entraîné une augmentation significative de la prévalence du diabète. La prise en charge de cette maladie dans des conditions d'incertitude, de violence et de pauvreté endémiques est extrêmement difficile. Le modèle de la microclinique permet d'instaurer un espace public d'échanges sociaux et communautaires au sein duquel les amis, la famille et les voisins peuvent participer tous ensemble à l'éducation, au traitement et aux séances de groupe, accéder avec d'autres à la technologie appropriée et encourager les comportements sains. Les participants qui s'investissent dans des microcliniques se sentent qualifiés pour prendre soin d'eux-mêmes et des autres. Le modèle de la microclinique offre la perspective d'une démarche durable du point de vue économique, social et politique en matière de soins de santé.

${ }^{1}$ Global Micro-Clinic Project, San Francisco, California, United States of America (Correspondence to D.E. Zoughbie: daniel.zoughbie@gmcproject.org).

Received: 28/01/07; accepted: 25/03/07

المجلة الصحية لشرق المتوسط، منظمة الصحة العالمية، المجلد الخامس عشر، العدد ع، 9 +. 


\section{Introduction}

Chronic diseases are a leading cause of death and disability in the world today. Noncommunicable conditions, including obesity and diabetes, account for $59 \%$ of the 57 million deaths annually. Around 177 million people are affected by diabetes, two-thirds of whom live in the developing world $[1,2]$. The growing prevalence of diabetes and obesity threatens to undermine struggling economies [3].

Although there is a strong economic and humanitarian argument to be made for the prevention and management of chronic diseases, poverty alleviation programmes such as the Millennium Development Goals have failed to list chronic diseases as a major priority. Thus, they are being ignored and underfunded [4].

\section{Burden of chronic disease in Palestine}

Increased urbanization, socioeconomic development and behavioural changes in the Eastern Mediterranean Region have led to a rise in chronic diseases such as diabetes. These trends have serious implications for the future growth of chronic noncommunicable diseases, and constitute a major public health problem $[5,6]$. In the context of endemic uncertainty, poverty, persistent violence and restricted movement, the burden of diabetes in the Occupied Palestinian Territory is great. A 2001 study found impaired glucose tolerance in 5.9\% of an urban survey population (492 men and women) and diabetes in $12.0 \%$ of the same population [7].

There is evidence that preventive measures in high-risk individuals, including proper self-management of diabetes, can reduce its prevalence and complications.
The American Diabetes Association suggests that self-monitoring of blood glucose is an important part of diabetes management that allows individuals to evaluate their response to therapy and to achieve desirable blood glucose levels. Self-monitoring of blood glucose enables diabetic individuals to interpret data and to adjust medication and behaviour accordingly [8]. A healthy diet and appropriate physical activity are other important components of effective therapy as they can contribute to improved blood glucose control, prevent diabetes mellitus in high-risk individuals and improve overall bodily health $[8]$.

Because individuals are connected to other individuals, their health is also connected to the health of those around them. Both negative and positive behaviours have the potential to be spread via social networks [9]. While medication can also be an important part of therapy, in places such as the Occupied Palestinian Territory, there are often severe shortages of medication due to closures, curfews, violence and economic hardship. General health and lifestyle information is provided hastily and superficially, if at all [10]. The prevention and management of diabetes in underserved regions requires effective social solidarity programmes that compliment existing services and bring together all available technical and human resources to solve significant public health problems.

\section{The diabetes micro-clinic study}

The existing Palestinian health care system continues to be undermined by geo-politics and pervasive conditions of uncertainty. In the D'heisheh refugee camp, for instance, it has been reported that a United Nations employed doctor sees about 170 patients a day [11]. With economic restrictions imposed 
in 2006, the World Health Organization warned of a growing financial and humanitarian crisis, which has resulted in high rates of unemployment, restricted access to services, unpaid health workers and severe shortages of medicines [12].

In 2005, a pilot micro-clinic project was established in the Bethlehem area and the D'heisheh refugee camp. Working with volunteer doctors, nurses and students, we created 50 diabetes "micro-clinics" composed of small groups of patients meeting in designated houses or business premises for the purpose of diabetes education, screening, treatment, monitoring and social solidarity [11]. Micro-clinics bring together human, technological and information resources within a given community to address a significant public health problem. They facilitate shared access to general education, specialist services and technologies such as personal blood glucose monitoring devices. Using lectures, workshops and group activities, the diabetes micro-clinics are vehicles of self-empowerment that encourage informed interaction with health care professionals. The micro-clinics create an infrastructure that is owned and operated by the participants. Ultimately, micro-clinics are the people.

The micro-clinic model establishes a public domain of community interaction whereby people who know each other as family, friends and neighbours can collectively access education, treatment and psychosocial support. The idea emerged from ethnographic observations showing that many Palestinians are not properly educated about diabetes. Family members and close friends heavily influence the perception of serious health problems. Moreover, people do not have the resources or information to purchase important technologies such as personal glucose monitoring systems, widely used in the United States and Europe [11]. Therefore, each micro-clinic (a group of approximately 3 to 6 individuals) voluntarily completes an educational programme, participates in structured and unstructured group activities, and shares the cost of maintaining a glucose meter. These machines are important as they allow for more intensive blood glucose control that is cost-effective and can significantly reduce diabetes-related complications [13] The machines, educational materials, and social activities create an interesting focal point for groups as they positively engage in improving the health and well-being of the community.

The micro-clinic project was implemented in 4 steps:

Step 1: Assessment and planning efforts were undertaken to identify existing resources, social networks and local volunteer leadership. This stage included planning and training sessions with volunteer doctors, nurses and students from the Bethlehem area and from the D'heisheh refugee camp.

Step 2: Although the Ministry of Health did not have any official involvement with this project, volunteer nurses, doctors and university faculty members from the Bethlehem area provided large educational lectures open to the community. These volunteers distributed supplemental educational booklets obtained from the United Nations Relief Works Agency (UNRWA). The lecture topics included the causes of diabetes, complications, prevention, management, diet and exercise [11]. These lectures were facilitated using local community centres, health committees and academic staff.

Step 3: The large lecture groups were then divided into smaller groups of about 20 individuals. Each person was able to ask personal questions and was tested by a

المجلة الصحية لشرق المتوسط، منظمة الصحة العالمية، المجلد الخامس عشر، العدد ع، 9 +. 
doctor or registered nurse using a personal glucose monitoring system (MediSense Precision QID systems were used because they do not require batteries and are locally available). Those who registered high readings or previously knew that they had diabetes moved on to the next step. These individuals were also referred to local doctors and nurses from the UNRWA, private clinics and Ministry of Health doctors or nurses when possible. In the Bethlehem area, existing services are either limited or expensive, and therefore many diabetic patients were not able to obtain regular access to such facilities.

Step 4: Individuals who registered high readings, and who were evaluated by health care professionals, were divided into "micro-clinics" - organically formed, selfselected groups of close friends, family and neighbours. Each micro-clinic was given a glucose monitor to share. During this phase, members of the micro-clinics were trained by a doctor or registered nurse in the use of the glucose monitors. This training included following relevant guidelines concerning the proper sterilization and waste disposal procedures for insulin needles, lancets and other sources of contamination [14].

As support groups, the micro-clinics are led by a volunteer leader-usually a family member-responsible for assisting in documenting readings, administering tests and promoting education and behavioural change. These micro-clinic groups participate in social activities together and receive ongoing education and follow-up visits from a registered nurse who serves as a local micro-clinic coordinator for approximately 1 year. The micro-clinic coordinator checks to make sure that the machines are working, being utilized properly and sterilization and waste disposal procedures are being adhered to. The coordinator also discusses behavioural changes, monitoring results and overall progress in the management of diabetes. This process helps diabetes patients interact with health care professionals in a more informed and empowered way. Working with local entrepreneurs, a cooperative system of purchasing replacement supplies was established to secure discounted prices for micro-clinic members.

\section{Evaluation}

Continuous evaluation takes place of what is and is not working at the local level. Several important observations were made during ethnographic fieldwork, focus groups and through individual discussions with 25 micro-clinic representatives.

\section{Micro-clinics facilitate community awareness and outreach}

The micro-clinics not only serve participants, but also impact on their immediate communities. Friends and neighbours mingle with micro-clinic participants and often ask about the programme and glucose meters. Some have subsequently asked to be screened for diabetes. As outreach centres, the micro-clinics are also functioning in emergencies. One undiagnosed woman who was feeling ill was rushed to the local doctor after her daughter, a micro-clinic participant, tested her and found an extremely high glucose level.

\section{Micro-clinics involve friends and family} In most micro-clinics, both participants and volunteers (a son, daughter, grandson, etc.) were shown how to use the machines. These youth volunteers, family members, and caregivers act as "staff" leaders of the micro-clinics and are vital to their effectiveness. The micro-clinics work from within the space of the home, encouraging prevention and management of a disease which is 
so greatly affected by domestic behaviour patterns.

Micro-clinics can be important in remote locations

Glucose monitors were also distributed to registered nurses, who were not previously equipped with basic medical technologies. They have used these resources for microclinic groups of patients in remote locations, enhancing their mobility and geographical health care capacity.

\section{Micro-clinics can be used as emergency support systems}

The micro-clinic model offers an emergency support system which can be implemented in various contexts including conflicts and natural disasters. For instance, during curfews in Bethlehem when it is prohibited to enter the streets, family, friends and neighbours can come together in the micro-clinic house and share food, medicine and services.

This testing and health awareness is of even greater importance during emergencies, given prolonged high stress levels and lack of supplies.

Micro-clinics spread positive behaviours and provide psychological support People "feel secure" and empowered in their micro-clinics, and share resources such as test strips when they run out. The micro-clinics also encourage behavioural changes, as participants take medicine and exercise in response to elevated glucose levels detected on the monitors.
Micro-clinics empower participants to take responsibility for their own health

Because the micro-clinic participants are encouraged and prepared to take a more central role in the prevention and management of diabetes and its complications, they are able to interact with health care professionals in a participatory manner.

The micro-clinic model offers the potential of scalability as well as social, economic and political sustainability, especially in conflict-ravaged and impoverished areas. It creates a social network that can be used to spread positive behaviours throughout a community. Most importantly, the microclinic model advances the notion that health care cannot simply be provided from the top down - it must also be provided from the bottom up.

\section{Acknowledgements}

The project was supported by grants and awards from the Donald A. Strauss Foundation, the Robert and Colleen Haas Scholars Program, the University of California, Berkeley, and the Firedoll Foundation. In addition to our many dedicated volunteers and participants, the author is grateful to Professor Roy for her advice, and to Professor David Matthews for his helpful comments in reviewing an earlier copy of this manuscript. Sole responsibility for this manuscript lies with the author.

More details of the Global Micro-Clinic Project are available at at: http://www gmcp.org.

\section{References}

1. Chronic disease risk factors. World Health Organization [online factsheet]. http:// www.who.int/dietphysicalactivity/publications/facts/riskfactors/en/index.html, accessed 24 November 2008).
2. Facts related to chronic diseases. Fact sheet: diabetes. Geneva, World Health Organization [online factsheet] (http:// www.who.int/hpr/gs.fs. diabetes.shtml, accessed 24 November 2008).

المجلة الصحية لشرق المتوسط، منظمة الصحة العالمية، المجلد الخامس عشر، العدد ع، 9 . ب 
3. Hossain P, Kawar B, El Nahas M. Obesity and diabetes in the developing world-a growing challenge. New England journal of medicine, 2007, 356 (3):213-5.

4. Fuster V. Cardiovascular disease and the UN millennium development goals: a serious concern. Nature clinical practice. Cardiovascular medicine, 2006, 3:401.

5. Alwan A, King H. Diabetes in the Eastern Mediterranean Region. World health statistics quarterly, 1992, 45:355-9.

6. Abdul-Rahim HF et al. The metabolic syndrome in the West Bank population. Diabetes care, 2001, 24:275-9.

7. Abdul-Rahim HF et al. Diabetes mellitus in an urban Palestinian population: prevalence and associated factors. Eastern Mediterranean health journal, 2001, 7(1/2):67-78.

8. American Diabetes Association. Standards of medical care for patients with diabetes mellitus. Diabetes care, 2002, 25:S33-49.

9. Christakis A, Fowler J. The spread of obesity in a large social network over 32 years. New England journal of medicine, 2007, 357:370-9.

10. Tsapogas $P$. Poverty stress and unmet needs: life with diabetes in the Gaza Strip. Diabetes voice, 2004, 49:13-6.
11. Zoughbie D. The Diabetes Micro-Clinic Project: on a mission to stop one of the most relentless killers in the West Bank [online article]. Berkeley, California, University of California Berkeley News Center, 2005 (http://www.berkeley.edu/news/ students/2005/palestine/palestine_about. shtml, accessed 25 November 2008).

12. Palestinian Health Ministry in financial crisis, WHO warns [press release]. Geneva, World Health Organization, 2006 (http://www.who.int/mediacentre/news/ releases/2006/pr46/en/index.html, accessed 25 November 2008).

13. Gray A et al. Cost effectiveness of an intensive blood glucose control policy in patients with type 2 diabetes: economic analysis alongside randomised controlled trial. British medical journal, 2000, 320:1373-8.

14. Diabetes: recommendations for persons undergoing blood glucose monitoring in evacuation centers for the prevention of hepatitis $B$ virus, hepatitis $C$ virus, and human immunodeficiency virus transmission. Disaster recovery fact sheet [online factsheet]. Atlanta, Georgia, Centers for Disease Control, 2005 (http://www.bt.cdc. gov/disasters/diabetes/, accessed 14 November 2008). 